\title{
Loss of Leucine Zipper Putative Tumor Suppressor 1 (LZTS1) Expression Contributes to Lymph Node Metastasis of Breast Invasive Micropapillary Carcinoma
}

\author{
Xin-Xin Wang $\cdot$ Bing-Bing Liu $\cdot$ Xiao Wu $\cdot$ Dan Su • \\ Zhengmao Zhu $\cdot$ Li Fu \\ Received: 18 January 2014 / Accepted: 20 February 2015 /Published online: 27 March 2015 \\ (C) The Author(s) 2015. This article is published with open access at Springerlink.com
}

\begin{abstract}
Breast invasive micropapillary carcinoma (IMPC) is a rare subtype of breast cancer with a high potential of lymph node metastasis, aggressive clinical behavior, and poor disease-free or overall survival. Expression of leucine zipper putative tumor suppressor 1 (LZTS1) was frequently lost or reduced in breast cancer tissues. This study investigated the expression of LZTS1 protein in breast IMPC tissues using immunohistochemistry. In addition, somatic LZTS1 mutations and promoter methylation were assessed to determine an association with clinicopathological data from IMPC patients. LZTS1 protein was downregulated in 62 (62\%) of 100 IMPC tissue samples and was significantly associated with lymph node metastasis $(P<0.05)$. A LZTS1 exon mutation occurred in one of the 53 IMPC cases analyzed, whereas a LZTS1 intron mutation occurred in 26 of 53 cases. Moreover, LZTS1 promoter was frequently methylated in IMPC samples and was associated with reduced LZTS1 expression levels in IMPC tissues. These data demonstrated that the loss of LZTS1 expression was associated with lymph node metastasis in patients with IMPC, and LZTS1 promoter methylation could be responsible for the loss of LZTS1 expression.
\end{abstract}

Xin-Xin Wang and Bing-Bing Liu contributed equally to this work.

\section{X.-X. Wang}

Department of Pathology, Beijing Youan Hospital of Capital Medical University, Beijing 100069, China

\section{X.-X. Wang • B.-B. Liu $\cdot$ L. Fu $(\bowtie)$}

Tianjin Medical University Cancer Institute and Hospital, Key

Laboratory of Cancer Prevention and Therapy, Key Laboratory of

Breast Cancer Prevention and Therapy, Huan Hu Xi Road,

Tianjin 300060, China

e-mail: tj.lzts1@gmail.com

$\mathrm{X} . \mathrm{Wu} \cdot \mathrm{D} . \mathrm{Su} \cdot \mathrm{Z} . \mathrm{Zhu}$

Department of Genetics and Cell Biology, Nankai University College of Life Sciences, Tianjin 300071, China
Keywords Breast IMPC $\cdot$ LZTS1 - Gene expression and promoter methylation

$\begin{array}{ll}\text { Abbreviations } \\ \text { LZTS1 } & \text { Leucine zipper putative tumor suppressor 1 } \\ \text { IMPC } & \text { Invasive micropapillary carcinoma } \\ \text { IDC } & \text { Invasive ductal carcinoma } \\ \text { DHPLC } & \begin{array}{l}\text { Denaturing high performance liquid } \\ \text { chromatography }\end{array}\end{array}$

Introduction

Breast cancer is the most frequently diagnosed cancer in women, accounting for 1.4 million new cases and an estimated more than 458,000 cancer-related deaths in 2008 worldwide (Global Cancer Facts \& Figures, 2nd Edition, American Cancer Society). Early stage breast cancer typically is not associated with symptoms. Risk factors of breast cancer include female gender, old age, inherited mutations (such as BRCA1 and BRCA2), family history of breast cancer, high breast tissue density, overweight or obese after menopause, use of menopausal hormone therapy (MHT), physical inactivity, and alcohol consumption (Global Cancer Facts \& Figures, 2nd Edition, American Cancer Society). These risk factors could activate oncogenes and silence tumor suppressor genes, leading to the development of breast cancer [1]. Moreover, the cause of death for breast cancer patients is usually due to metastasis. Thus, the most important prognostic factor in breast cancer remains the lymph node status, which strongly correlates with disease-free and overall survival of the patients.

Clinically, breast cancer is classified as carcinoma in situ or invasive ductal carcinoma (IDC). Histologically, the vast 
majority of breast cancer is characterized as IDC. Invasive micropapillary carcinoma (IMPC) is a rare subtype of IDC and was listed by the World Health Organization classification in 2003 [2]. The incidence of IMPC is approximately $4.18 \%$, and IMPC is frequently mixed with IDC, not otherwise specified (NOS) and a pure IMPC is the micropapillary component $\geq 90 \%$. In addition, IMPC is associated with a high invasion potential to lymphatic vessels and metastasis to the axillary lymph nodes [3-5]. However, the underlying mechanisms are poorly understood.

Leucine zipper putative tumor suppressor 1 (LZTS1) was identified by Ishii et al. in 1999 [6]. Ubiquitous expression of LZTS1 protein has been detected in normal tissues; however, it is reduced or lost in different cancer tissues and cells, including gastric, lung, bladder, oral, and kidney cancers [6-13]. Restoration of LZTS1 expression in LZTS1-negative cancer cells resulted in the suppression of tumorigenicity, reduced tumor cell growth, and arrested cells at the late $\mathrm{S}_{-} \mathrm{G}_{2} / \mathrm{M}$ phase of the cell cycle. Previous studies have shown that LZTS1 expression levels are downregulated in breast cancer tissue and cell lines [14]. Our own data confirmed that LZTS1 expression was reduced or lost in IDC, and reduced LZTS1 expression was associated with lymph node metastasis [15]. Hypermethylation of LZTS1 CpG islands could be responsible for the reduced expression of LZTS1 in cancer cells [7, 8]. In this study, we detected the expression of LZTS1 protein in IMPC tissues using immunohistochemistry. In addition, we determined whether somatic LZTS1 mutations and promoter methylation were associated with clinicopathological data from IMPC patients.

\section{Materials and Methods}

Study Population

In total, 100 pure IMPC breast tissue specimens and 20 normal breast tissues (used as a control) were retrospectively retrieved from The Department of Breast Cancer Pathology and
Research Laboratory of the Cancer Hospital of Tianjin Medical University in Tianjin, China. These patients were surgically treated in our hospital between October 2005 and December 2009 and histologically diagnosed as IMPC, independently by two pathologists using the WHO criteria [1]. Since our previous study demonstrated that IMPC was significantly associated with lymph nodes metastasis [16], we grouped them as a single disease entity for this study. All of the patients were women with a mean age of 54 years (range: 29-83 years). None of the patients received preoperative radiation or chemotherapy. Use of human tissue in this study was approved by the Ethics Committee of the Tumor Hospital of Tianjin Medical University, and each patient signed a inform consent.

Immunohistochemistry

Formalin-fixed and paraffin-embedded tissue blocks were cut into sections. For immunohistochemistry, the tissue sections were first deparaffinized in xylene and rehydrated in a series of graded alcohol. For antigen retrieval, the sections were submerged in $5 \mathrm{mM}$ citrate buffer ( $\mathrm{pH} 6.0$ ), cooked for $1.5 \mathrm{~min}$ in a pressure cooker, and then incubated with $3 \% \mathrm{H}_{2} \mathrm{O}_{2}$ in phosphate buffered saline (PBS) at the room temperature for $30 \mathrm{~min}$ to inactivate endogenous peroxidase. The sections were further incubated with $10 \%$ normal rabbit serum for $10 \mathrm{~min}$ to block non-specific binding of the secondary antibody. Next, the sections were incubated with a polyclonal goat anti-LZTS1 antibody (Santa Cruz Biotechnology, Santa Cruz, CA, USA) at a dilution of $1: 75$ at $4{ }^{\circ} \mathrm{C}$ overnight. The negative control section was incubated with a preimmune serum to replace the antibody. On the next day, the sections were washed with PBS thrice, incubated with a biotinylated anti-goat antibody, and then incubated with streptavidin-biotin-peroxidase (Zhongshan Golden Bridge, Beijing, China). Diaminobenzidine was used as a chromogen substrate to visualize the positive signal. Then, the sections were washed in distilled water and shortly counterstained with hematoxylin and mounted. The sections were finally reviewed under a microscope independently by two

Table 1 LZTS1 primers

\begin{tabular}{|c|c|c|c|}
\hline Primer location & DNA sequence & $\operatorname{Tm}\left({ }^{\circ} \mathrm{C}\right)$ & Size PCR product (bp) \\
\hline Exon 1 & 5'-CTCACGGAGCCACGACTG-3' & 58 & 492 \\
\hline \multirow[t]{4}{*}{ Exon 2} & $\begin{array}{l}\text { 5'-CACCCCCATTTTGCTTTC-3' } \\
\text { 5'-CTGGCTCAAGGTCGGCAC-3' }\end{array}$ & \multirow[t]{3}{*}{62} & 460 \\
\hline & $\begin{array}{l}\text { 5'-GCTTGCTACCTCCGTCGG-3' } \\
\text { 5'-TGGTCACACCCGTGGGACC-3' }\end{array}$ & & 389 \\
\hline & $\begin{array}{l}\text { 5'-GCTGGCTCTTCTGCGAGGC-3' } \\
\text { 5'-GGGCCCGGAGCCCAAAGG-3' }\end{array}$ & & 406 \\
\hline & $\begin{array}{l}\text { 5'-AGTCGATCCCCCAACATG-3' } \\
\text { 5'-CCGGGCCACCGCATCCGGAGT-3' }\end{array}$ & \multirow[t]{3}{*}{64} & \multirow[t]{2}{*}{435} \\
\hline \multirow{2}{*}{ Exon 3} & $\begin{array}{l}\text { 5'-GTGGGCGGCCCCATGTC-3' } \\
\text { 5'-GGGCCTGGAGCTGGAGGTCTGT-3' }\end{array}$ & & \\
\hline & 5'-GGGGATGCACGGGAGAGC-3' & & 528 \\
\hline
\end{tabular}


Fig. 1 Immunohistochemical detection of LZTS1 expression in normal breast, and IMPC tissues. $\mathbf{a}$ and $\mathbf{b}$ Expression of LZTS1 protein in the cytoplasm of normal breast ductal epithelia. c Strong expression $(+++)$ of LZTS1 protein in IMPC tissues. $\mathbf{d}$ Absence of LZTS1 protein in IMPC tissue. a, $\mathbf{c}, \mathbf{d}$ at $\times 100$ magnification and $\mathbf{b}$ at $\times 400$ magnification
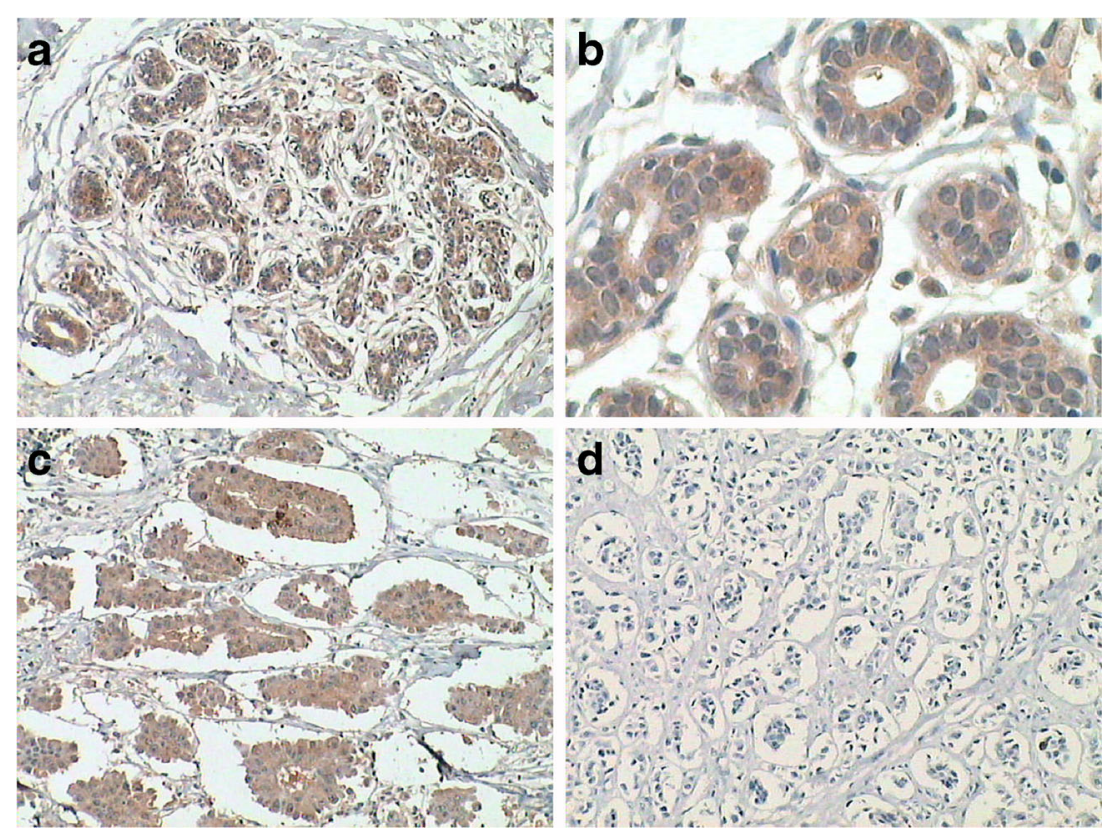

pathologists and blindly scored for LZTS1 immunoreactivity into four categories using a previously reported scoring method [9]: +++ or strong (96-100\% positive cells); ++ or moderate (51-95\% positive cells); + or weak ( $2-50 \%$ positive cells); and —or absent $(<2 \%$ positive cells).

\section{Denaturing High Performance Liquid Chromatography (DHPLC) Analysis}

We performed DHPLC analysis to sequence LZTS1 mutations. We designed different primers to amplify the coding regions of the three exons of LZTS1 (Table 1). Genomic DNA was extracted form paraffin sections using a DNA tissue kit (Qiagen, Germany) according to the manufacturer's instructions and then subjected to PCR amplification using AmpliTaq Gold (Applied Biosystems, USA) in a final volume of $25 \mathrm{ml}$. The system control software (Transgenomic Navigator Software, Transgenomic, USA) gave the running conditions of each amplicon. PCR product was applied to a DNASep column (Transgenomic-Wave 3500A DHPLC system, Transgenomic). All of the PCR products that produced tumor-specific shifts on DHPLC were re-amplified and sequenced with both forward and reverse primers using BigDye sequencing chemistry (Applied Biosystems). The PCR products that resulted in DHPLC shifts with both tumor and germline DNA were also sequenced to identify polymorphisms.

Bisulfite Treatment, Methylation-Specific PCR (MSP), and DNA Sequencing

We treated genomic DNA with bisulfite as previously described [17]. Briefly, $2 \mathrm{~g}$ of genomic DNA was diluted into $50 \mathrm{ml}$ of distilled water and $5.5 \mathrm{ml}$ of $2 \mathrm{M} \mathrm{NaOH}$ was added. The mixture was then incubated at $37{ }^{\circ} \mathrm{C}$ for $10 \mathrm{~min}$. After that, $30 \mathrm{ml}$ of freshly prepared $10 \mathrm{mM}$ hydroquinone (Sigma, St Louis, MO, USA) and $520 \mathrm{ml}$ of freshly prepared $3 \mathrm{M}$ sodium bisulfite (pH 5.0) (Sigma) were added to each tube. After thorough mixing, mineral oil was added to each tube. The tubes were incubated at $50{ }^{\circ} \mathrm{C}$ for $16 \mathrm{~h}$. On the next day, $1 \mathrm{ml}$ of DNA wizard cleanup resin was added (Promega, Madison, WI, USA). The modified genomic DNA was purified and eluted with $50 \mathrm{ml}$ of water following the instructions in the kit. After adding $5.5 \mathrm{ml}$ of $3 \mathrm{M} \mathrm{NaOH}$ and incubating at room temperature for $5 \mathrm{~min}, 1 \mathrm{ml}$ of glycogen (Sigma, St Louis, MO, USA) was added to each sample and then precipitated with $33 \mathrm{ml}$ of $10 \mathrm{M} \mathrm{NH}_{4} \mathrm{Ac}$ (Sigma) and three volumes of ethanol. The DNA samples were then resuspended in $20 \mathrm{ml}$ distilled water and stored at $-20^{\circ} \mathrm{C}$ until use.

For the MSP analysis of LZTS1 promoter CpG methylation, we designed two pairs of primers to cover the $\mathrm{CpG}$ enriched region of the LZTS1 promoter as described previously [15]. PCR amplification was performed in a volume of $25 \mathrm{ml}$ containing $2 \mathrm{ml}$ of bisulfite-treated DNA. The PCR cycles consisted of an initial denaturing at $94{ }^{\circ} \mathrm{C}$ for $5 \mathrm{~min}$, followed by 40 cycles of $94{ }^{\circ} \mathrm{C}$ for $20 \mathrm{~s}, 60^{\circ} \mathrm{C}$ for $20 \mathrm{~s}$ and $72^{\circ} \mathrm{C}$ for $30 \mathrm{~s}$, and a final step at $72{ }^{\circ} \mathrm{C}$ for $5 \mathrm{~min}$. PCR products were then cloned into a pGEM-

Table 2 LZTS1 expression in IMPC and normal breast tissues

\begin{tabular}{lccccc}
\hline Pathologic type & \multicolumn{2}{l}{ LZTS1 expression } & & \multirow{2}{*}{$\chi^{2}$} & $P$ value \\
\cline { 2 - 3 } & \multicolumn{1}{l}{$-/+$} & $++/+++$ & & \\
\hline IMPC & 62 & 38 & & \\
Normal & 0 & 20 & 25.655 & 0.000 \\
\hline
\end{tabular}


Table 3 Association of LZTS1 expression with clinicopathological data from IMPC patients

\begin{tabular}{|c|c|c|c|c|c|c|}
\hline \multirow[t]{2}{*}{ Clinicopathological character } & \multicolumn{4}{|c|}{ LZTS1 expression } & \multirow[t]{2}{*}{$\mathrm{r}_{\mathrm{s}}$} & \multirow[t]{2}{*}{$P$ valu } \\
\hline & $(-)$ & $(+)$ & $(++)$ & $(+++)$ & & \\
\hline \multicolumn{7}{|l|}{ Age $($ mean age $=54)$} \\
\hline$<54$ years old & 18 & 18 & 7 & 4 & & \\
\hline$\geq 54$ years old & 15 & 11 & 17 & 10 & 0.222 & 0.026 \\
\hline \multicolumn{7}{|l|}{ Tumor size } \\
\hline$<2 \mathrm{~cm}$ & 4 & 5 & 7 & 1 & & \\
\hline$\geq 2 \mathrm{~cm}$ & 29 & 24 & 17 & 13 & -0.062 & 0.541 \\
\hline \multicolumn{7}{|l|}{ Histological grade } \\
\hline I & 2 & 1 & 5 & 3 & & \\
\hline II & 26 & 25 & 16 & 9 & & \\
\hline III & 5 & 3 & 3 & 2 & -0.143 & 0.155 \\
\hline \multicolumn{7}{|l|}{ Lymph node metastasis } \\
\hline- & 2 & 1 & 3 & 4 & & \\
\hline+ & 31 & 28 & 21 & 10 & -0.210 & 0.036 \\
\hline \multicolumn{7}{|l|}{ Lymph node grade } \\
\hline pN0 & 2 & 1 & 3 & 4 & & \\
\hline $\mathrm{pN} 1$ & 7 & 10 & 10 & 5 & & \\
\hline $\mathrm{pN} 2$ & 14 & 12 & 6 & 3 & & \\
\hline $\mathrm{pN} 3$ & 10 & 6 & 5 & 2 & -0.265 & 0.008 \\
\hline \multicolumn{7}{|l|}{ ER } \\
\hline- & 16 & 8 & 8 & 3 & & \\
\hline+ & 17 & 21 & 16 & 11 & 0.178 & 0.077 \\
\hline \multicolumn{7}{|l|}{ PR } \\
\hline- & 6 & 7 & 7 & 5 & & \\
\hline+ & 27 & 22 & 17 & 9 & -0.137 & 0.174 \\
\hline \multicolumn{7}{|l|}{ HER2 } \\
\hline$-/+$ & 27 & 22 & 17 & 11 & & \\
\hline$++/+++$ & 6 & 7 & 7 & 3 & 0.067 & 0.506 \\
\hline
\end{tabular}

T Easy Vector (Promega), and DNA was sequenced by Invitrogen (Carlsbad, CA, USA).
Statistical Analysis

Statistical analyses were performed using a Mann-Whitney $U$ test, Spearman's Rank-Correlation test, Student's $t$ test and $\chi^{2}$ test, respectively. SPSS 15.0 software (SPSS, Chicago, IL, USA) was used to analyze the dat. A 2 -sided $P<0.05$ was considered as statistically significant.

\section{Results}

Clinicopathological Characteristics of IMPC Patients

Among these 100 Chinese IMPC patients, their mean age was 54 years old. Pathologically, 83 cases $(83 \%)$ had a tumor size larger than $2 \mathrm{~cm}$; 90 cases (90\%) showed lymph node metastasis, and 23 (23\%) were lymph node grade III, while 89 cases (89\%) had moderate or poor differentiated tumor and 25 cases ( $25 \%$ ) were triple-negative immune phenotype of tumor.

LZTS1 Expression in IMPC Tissues and Its Association with Clinicopathological Data from IMPC Patients

LZTS1 protein was expressed in normal breast ductal epithelial tissues with a granular localization in the cytoplasm (Fig. 1). In contrast, $62 \%(62 / 100)$ of the IMPC tissue had LZTS1 protein loss or down-regulation $(14+++, 24++, 29+$, and $33-)$ and significantly lower than normal tissues $(\chi 2=$ 25.655, $P=0.000$; Table 2).

Moreover, we found that among these different LZTS1 expression from strong to absent level, lymph node metastasis rate were $71.4 \%, 87.5 \%, 96.5 \%, 93.5 \%$, respectively. The expression of LZTS1 protein in IMPC tissue was inversely associated with IMPC lymph node metastasis $(\mathrm{rs}=-0.210$, $P=0.036)$ and lymph node grade ( $\mathrm{rs}=-0.265, P=0.008)$. However, there was no significant association of LZTS1 expression with patient age, tumor size, histological grade, ER, PR and HER2 expression (Table 3).
Fig. 2 DNA sequencing data of MSP products of a pair of IMPC $(T)$ and normal $(N)$ tissues. A representative wild-type LZTS1 sequence is shown at the top. Each of the three cytosines $(C)$ in a CpG dinucleotide was converted to thymine $(T)$ in the normal tissue, but not in the cancer tissue

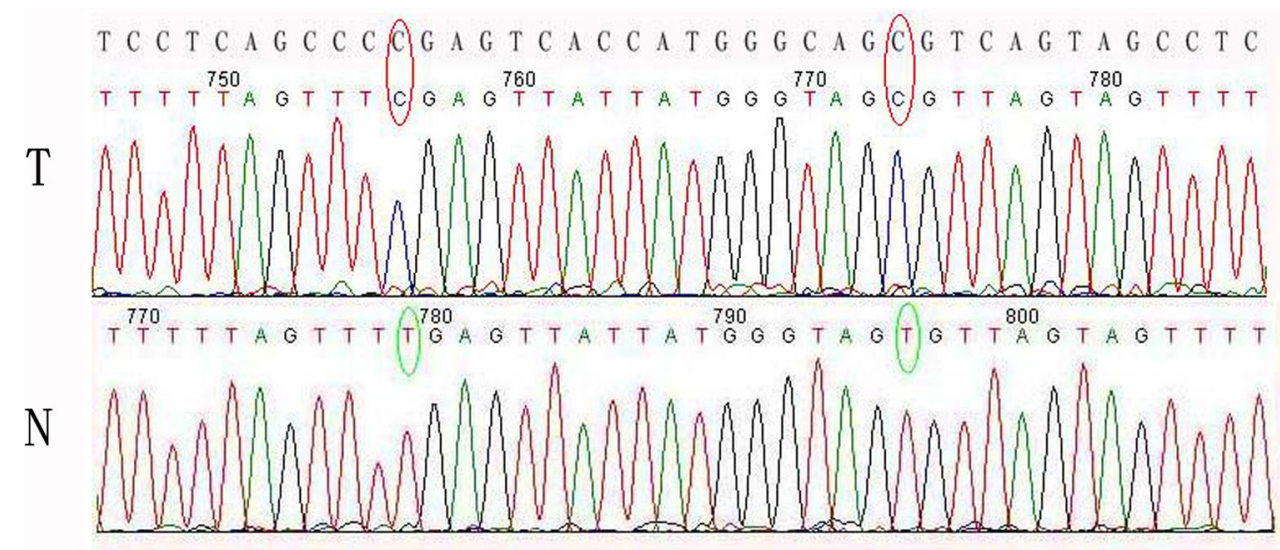


Fig. 3 LZTS1 promoter methylation. LZTS1 promoter methylation level of each of these 18 CpG dinucleotides in IMPC, and compared to normal breast tissues $(P<0.05)$

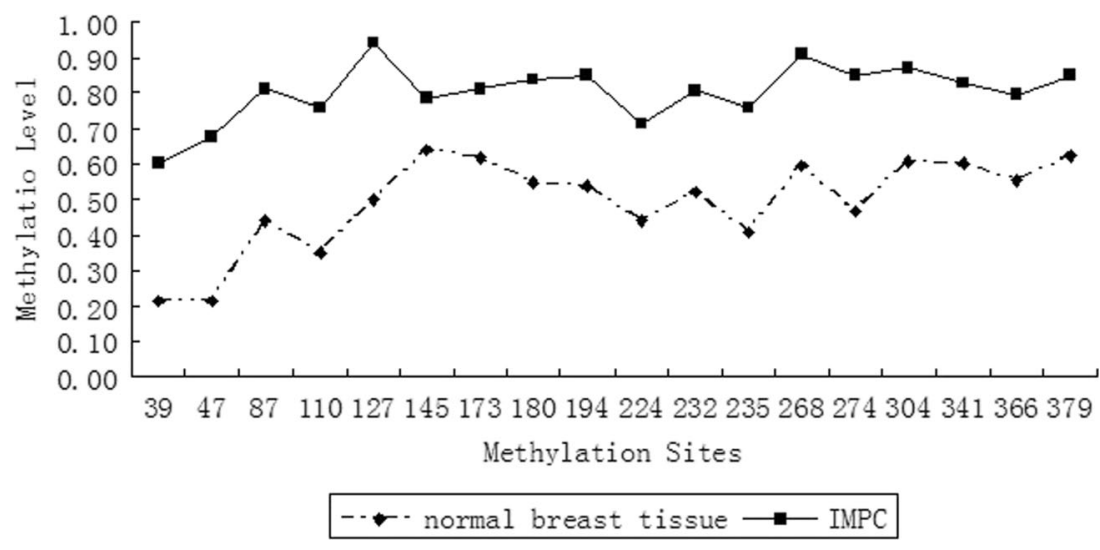

\section{LZTS1 Somatic Mutation in IMPC Tissues}

We extracted DNA from 100 IMPC paraffin-embedded tissues. However, we could only analyze 53 of the DNA samples. In IMPC tissue samples, mutations were localized on exon 3 (C3927G, Leu $>\mathrm{Val})$. Another base change was detected in the intron region (C6544T) in 25/53 of the IMPC samples. These changes were not found in the corresponding normal tissues.

\section{Methylation of LZTS1 Promoter in IMPC Tissues}

We analyzed LZTS1 promoter methylation in 18 IMPC samples, and 9 normal breast tissue samples (as a control). After MSP, we cloned PCR products into a pGEM-T Easy Vector and randomly picked ten clones for DNA sequencing from each tumor sample. Figure 2 shows DNA sequence results from normal and cancer tissues. Two CG sites were methylated in the IMPC tumor samples, but not in the normal tissues. The methylation level for each of the $18 \mathrm{CG}$ dinucleotides within the PCR product is shown in Fig. 3. We found that $18 / 18(100 \%)$ of the IMPC samples had LZTS1 promoter methylation. In contrast, $0 / 9(0 \%)$ of the normal breast tissue samples had LZTS1 promoter methylation. Furthermore, Statistical analysis revealed LZTS1 promoter methylation was associated with the loss of LZTS1 protein expression (Table 4, $P<0.05$ ).

\section{Discussion}

In this study, we first detected LZTS1 expression in 100 IMPC tissues. We found that LZTS1 expression was reduced or lost in IMPC, and reduced LZTS1 expression was associated with lymph node metastasis. Many studies have shown that LZTS1 expression is downregulated in different types of human cancers, including cancers of the breast, gastric, lung, bladder, oral cavity, prostate, and kidney [6-13]. In addition, reduced LZTS1 expression was associated with LZTS1 promoter methylation or mutation $[7,8]$. After that, we determined whether somatic LZTS1 mutations were associated with clinicopathological data from IMPC patients. To date, studies have detected LZTS1 mutations in different cancers, but they are uncommon. For example, Ishii H et al. [6] analyzed 194 cancer samples, including 72 primary esophageal cancer samples, 18 esophageal cancer cell lines, 24 primary prostate cancer samples, 3 prostate cancer cell lines, 39 primary breast cancer samples, 25 breast cancer cell lines, 8 primary ovarian cancer samples, 4 leukemic cell lines, and 1 cervical cancer cell line. They found two point mutations in two cases of esophageal cancer tissues and one point mutation at codon 501 in the prostate cancer PC3 cell line. Vecchione et al. [8] found a missense mutation in one case of gastric carcinoma that also had LZTS1 loss. Arnold et al. analyzed LZTS1 coding regions in 87 primary ovarian adenocarcinoma samples using DHPLC, but only detected a single silent somatic mutation [18]. In this study, we also found one of these 53 IMPC samples had a mutation at exon 3, while 25 of the 53 IMPC samples had a base change in the intron region of LZTS1. But LZTS1 mutation was not the main cause for loss of LZTS1 expression in IMPC.

Gene promoter methylation is a common epigenetic mechanism that transcriptionally inactivates gene expression in different human cancers [19]. Our previous study showed that LZTS1 promoter methylation was associated with LZTS1 downregulation in IDC [15]. However, LZTS1 promoter was more frequently methylated in IMPC samples and was associated with reduced levels of LZTS1 expression, indicating that LZTS1 plays a role in promoting IMPC progression at

Table 4 Association between LZTS1 expression and methylation in IMPC tissues

\begin{tabular}{llllll}
\hline \multirow{2}{*}{ LZTS1 expression } & \multicolumn{2}{l}{ Methylation } & & $\mathrm{r}_{\mathrm{s}}$ & $P$ value \\
\cline { 2 - 4 } & Low & Median & High & & \\
\hline$+++/+$ & 3 & 0 & 1 & & \\
$-/+$ & 1 & 2 & 11 & -0.607 & 0.008 \\
\hline
\end{tabular}


least through the promoter methylation-mediated transcriptional repressor. Therefore, we hypothesized that reactivation of the methylation-silenced gene could restore LZTS1 expression and inhibit IMPC metastasis. The quantitative detection of LZTS1 might be useful for predicting potential of breast cancer metastasis. Indeed, our previous study showed that reexpression of LZTS1 in the highly metastatic MDA-MB-231 cell line resulted in an inhibition of cancer cell proliferation, migration and invasion, and suppression of epithelial-tomesenchymal transition [20]. However, further studies are needed to confirm this hypothesis.

Our current study is just proof-of-principle and larger sample sizes are needed to confirm our current data. In addition, survival data are needed to determine whether there is an association between LZTS1 expression and overall survival in IMPC patients. Finally, mechanistic studies are needed to investigate the mechanism responsible for LZTS1 promoter methylation and to investigate the role and functions of LZTS1 protein in IMPC.

Acknowledgments This work was supported in part by grants from the National Natural Science Foundation of China (\#30870980, \#30625032, and \#30930038), the National Key Scientific Program of China (\#2009CB521700 and \#2009CB918903) and Beijing Natural Science Foundation (\#7133236).

Conflict of interest The authors declare there is no conflict of interest in this work.

Open Access This article is distributed under the terms of the Creative Commons Attribution License which permits any use, distribution, and reproduction in any medium, provided the original author(s) and the source are credited.

\section{References}

1. Lakhani SR, Ellis IO, Schnitt SJ, Tan PH, van de Vijver MJ (2011) WHO classification of tumors of the breast. IARC Press, Lyon, pp 14-17

2. Tavassoli FA, Devilee P (2003) WHO classification of tumors. Pathology \& genetics, tumours of the breast and female genital organs. IARC Press, Lyon, $\mathrm{p} 10$

3. Nassar H, Wallis T, Andea A, Dey J, Adsay V, Visscher D (2001) Clinicopathologic analysis of invasive micropapillary differentiation in breast carcinoma. Mod Pathol 14:836-841

4. Walsh MM, Bleiweiss IJ (2001) Invasive micropapillary carcinoma of the breast: eighty cases of an underrecognized entity. Hum Pathol 32:583-589

5. Pettinato G, Manivel CJ, Panico L, Sparano L, Petrella G (2004) Invasive micropapillary carcinoma of the breast: clinicopathologic study of 62 cases of a poorly recognized variant with highly aggressive behavior. Am J Clin Pathol 121:857-866
6. Ishii H, Baffa R, Numata SI, Murakumo Y, Rattan S, Inoue H, Mori M, Fidanza V, Alder H, Croce CM (1999) The FEZ1 gene at chromosome 8p22 encodes a leucine-zipper protein, and its expression is altered in multiple human tumors. Proc Natl Acad Sci U S A 96: 3928-3933

7. Toyooka S, Fukuyama Y, Wistuba II, Tockman MS, Minna JD, Gazdar AF (2002) Differential expression of FEZ1/LZTS1 gene in lung cancers and their cell cultures. Clin Cancer Res 8:2292-2297

8. Vecchione A, Ishii H, Shiao YH, Trapasso F, Rugge M, Tamburrino JF, Murakumo Y, Alder H, Croce CM, Baffa R (2001) Fez1/lzts1 alterations in gastric carcinoma. Clin Cancer Res 7:1546-1552

9. Vecchione A, Ishii H, Baldassarre G, Bassi P, Trapasso F, Alder H, Pagano F, Gomella LG, Croce CM, Baffa R (2002) FEZ1/LZTS1 is down-regulated in high-grade bladder cancer, and its restoration suppresses tumorigenicity in transitional cell carcinoma cells. Am J Pathol 160:1345-1352

10. Nonaka D, Fabbri A, Roz L, Mariani L, Vecchione A, Moore GW, Tavecchio L, Croce CM, Sozzi G (2005) Reduced FEZ1/LZTS1 expression and outcome prediction in lung cancer. Cancer Res 65: 1207-1212

11. Knowles MA, Aveyard JS, Taylor CF, Harnden P, Bass S (2005) Mutation analysis of the $8 \mathrm{p}$ candidate tumour suppressor genes DBC2 (RHOBTB2) and LZTS1 in bladder cancer. Cancer Lett 225: $121-130$

12. Ono K, Uzawa K, Nakatsuru M, Shiiba M, Mochida Y, Tada A, Bukawa H, Miyakawa A, Yokoe H, Tanzawa H (2003) Downregulation of FEZ1/LZTS1 gene with frequent loss of heterozygosity in oral squamous cell carcinomas. Int J Oncol 23:297-302

13. Vecchione A, Galetti TP, Gardiman M, Ishii H, Giarnieri E, Pagano F, Gomella LG, Croce CM, Baffa R (2004) Collecting duct carcinoma of the kidney: an immunohistochemical study of 11 cases. BMC Urol 4:11

14. Ishii H, Vecchione A, Murakumo Y, Baldassarre G, Numata S, Trapasso F, Alder H, Baffa R, Croce CM (2001) FEZ1/LZTS1 gene at 8 p22 suppresses cancer cell growth and regulates mitosis. Proc Natl Acad Sci U S A 98:10374-10379

15. Chen L, Zhu Z, Sun X, Dong XY, Wei J, Gu F, Sun YL, Zhou J, Dong JT, Fu L (2009) Down-regulation of tumor suppressor gene FEZ1/ LZTS1 in breast carcinoma involves promoter methylation and associates with metastasis. Breast Cancer Res Treat 116:471-478

16. Guo X, Chen L, Lang R, Fan Y, Zhang X, Fu L (2006) Invasive micropapillary carcinoma of the breast: association of pathologic features with lymph node metastasis. Am J Clin Pathol 126:740-746

17. Herman JG, Graff JR, Myöhänen S, Nelkin BD, Baylin SB (1996) Methylation-specific PCR: a novel PCR assay for methylation status of CpG islands. Proc Natl Acad Sci U S A 93:9821-9826

18. Arnold JM, Choong DY, Lai J, Campbell IG, Chenevix-Trench G (2006) Mutation and expression analysis of LZTS1 in ovarian cancer. Cancer Lett 233:151-157

19. Baylin SB, Herman JG, Graff JR, Vertino PM, Issa JP (1998) Alterations in DNA methylation: a fundamental aspect of neoplasia. Adv Cancer Res 72:141-196

20. Wang XX, Zhu Z, Su D, Lei T, Wu X, Fan Y, Li X, Zhao J, Fu L, Dong JT, Fu L (2011) Down-regulation of leucine zipper putative tumor suppressor 1 is associated with poor prognosis, increased cell motility and invasion, and pithelial-to-mesenchymal transition characteristics in human breast carcinoma. Hum Pathol 42:1410-1419 